\title{
Nebulized Hypertonic Saline Via Positive Expiratory Pressure Versus Via Jet Nebulizer in Patients With Severe Cystic Fibrosis
}

\author{
Oisin J O'Connell MD, Carmel O'Farrell, Mike J Harrison MB, Joseph A Eustace MD, \\ Michael T Henry MD, and Barry J Plant MD
}

\begin{abstract}
BACKGROUND: Nebulized hypertonic saline is a highly effective therapy for patients with cystic fibrosis (CF), yet $10 \%$ of patients are intolerant of hypertonic saline administered via jet nebulizer. Positive expiratory pressure (PEP) nebulizers splint open the airways and offers a more controlled rate of nebulization. METHODS: In 4 consecutive adult $C F$ patients who were intolerant of hypertonic saline via jet nebulizer, we nebulized $6 \%$ hypertonic saline via a PEP nebulizer. We measured the number of days the patients required intravenous antibiotics from enrollment to study end, compared to an equal period before PEP, and the mean time between the patients' 3 most recent infective pulmonary exacerbation episodes before PEP to their next exacerbation after PEP. Patients also completed a Likertscale adverse-effects questionnaire on hypertonic saline via PEP versus jet nebulizer. RESULTS: The 4 patients had severe CF pulmonary disease and all fully tolerated hypertonic saline via PEP, for 77, 92, 128, and 137 days, respectively until the study end date. There were fewer days of antibiotics in 3 of the 4 patients, from 45 to 20 days, 66 to 14 days, and 28 to 0 days (mean relative risk reduction 53\%, $P=.11)$. The other patient had 63 days of antibiotics during both the PEP and the jet nebulizer periods. There was a mean 3.6-fold longer time to next infective pulmonary exacerbation during the PEP period $(P=.07)$. Adverse effects were less with PEP: chest tightness 68\% $(P=.04)$, bad taste 62\% $(P=.06)$, cough 47\% $(P=.10)$, and sore throat 50\% $(P=.20)$. CONCLUSIONS: Hypertonic saline via PEP nebulizer benefits CF patients who do not tolerate hypertonic saline via jet nebulizer. Key words: cystic fibrosis; CF; hypertonic saline; nebulizer; positive expiratory pressure; PEP; antibiotics. [Respir Care 2011; 56(6):771-775. () 2011 Daedalus Enterprises]
\end{abstract}

\section{Introduction}

Cystic fibrosis (CF) is the most common life-threatening autosomal recessive disease in Ireland, with an inci-

\footnotetext{
Dr O'Connell, Ms O'Farrell, Dr Harrison, Dr Henry, and Dr Plant are affiliated with the Cork Adult Cystic Fibrosis Centre, Department of Respiratory Medicine, Cork University Hospital, University College Cork, Wilton, Cork, Ireland. Dr Eustace is affiliated with the Department of Renal Medicine, Cork University Hospital, University College Cork, Cork, Ireland.
}

The authors have disclosed no conflicts of interest.

Supplementary material related to this paper is available at http:// www.rcjournal.com.

Correspondence: Barry Plant MD, Cork Adult Cystic Fibrosis Centre, Cork University Hospital, University College Cork, Wilton, Cork N/a Ireland. E-mail: barry.plant@hse.ie.

DOI: $10.4187 /$ respcare.00866 dence of 1 in 1,461 births. ${ }^{1} \mathrm{CF}$ is characterized by mucus retention, bacterial infection, and inflammation, leading to lung damage and ultimately respiratory failure. CF therapies aim to improve mucociliary clearance, reduce bacterial load, and lower airway inflammation. ${ }^{2}$

See the Related Editorial on Page 886

A mutation in the $\mathrm{CF}$ transmembrane receptor gene results in abnormal ion transport across the respiratory epithelium. ${ }^{3}$ The primary pathophysiological defect is thought to be depletion of the airway surface liquid. The isotonic volume hypothesis proposes that the defective CF transmembrane receptor leads to excessive absorption of fluid from the airway surface liquid and a below-normal airway surface liquid volume (but of normal tonicity), ${ }^{4}$ which impairs mucociliary clearance, and the retained mucus is a locus of infection. Nebulized hypertonic saline induces an osmotic gradient that 


\section{Hypertonic Saline Via Positive Expiratory Pressure in Patients With Cystic Fibrosis}

increases the airway surface liquid, increases mucociliary clearance, and decreases CF pulmonary exacerbations.

Seven-percent hypertonic saline via jet nebulizer significantly reduces the $\mathrm{CF}$ pulmonary exacerbation rate and, thus, antibiotic use. ${ }^{5,6}$ As extrapolated from the original study, 5 jet nebulization of hypertonic saline is associated with almost $10 \%$ treatment intolerance, predominantly secondary to cough, bad taste, and bronchospasm.

\section{Methods}

This study was approved by the clinical research ethics committee of the Cork teaching hospitals. In CF patients who have previously failed jet-nebulized hypertonic saline because of intolerable adverse effects (eg, cough, bad taste, and bronchospasm), we studied patient tolerance of hypertonic saline administered via a positive expiratory pressure (PEP) system. We compared the exacerbation rate and antibiotic use during the jet-nebulizer period and the PEP-nebulizer period.

\section{Positive Expiratory Pressure Nebulizer System}

The PEP nebulizer system we used (Pari PEP-System 1 with Pari LC Plus nebulizer chamber, Pari Respiratory Equipment, Midlothian, Virginia) is a flow-resistor device with an adjustable restricted orifice that produces exhalation resistance of $10-20 \mathrm{~cm}$ of $\mathrm{H}_{2} \mathrm{O}$. PEP splints open the airways and provides a more controlled rate of nebulization. $^{7}$ Nebulization of bronchodilators with PEP is well established in bronchospastic patients. ${ }^{8}$

\section{Patients}

From May 16 to July 15, 2008, we recruited all successive adult CF patients in the Cork Adult Cystic Fibrosis Centre, Cork University Hospital, Cork, Ireland, who had previously failed trials of $6 \%$ hypertonic saline via jet nebulizer (Porta-Neb compressor [Respironics, Murrysville, Pennsylvania] and Sidestream nebulizer [Respironics, Murrysville, Pennsylvania] or Pari LC Plus nebulizer [Pari Respiratory Equipment, Midlothian, Virginia]) secondary to adverse effects (ie, the patient was unwilling to continue the therapy and/or had a $>15 \%$ decline in $\mathrm{FEV}_{1}$, after 2 separate trials of hypertonic saline via jet nebulizer). Our protocol of repeated hypertonic saline trials is based on findings that airway hyper-responsiveness to hypertonic saline can be a transient phenomenon. ${ }^{9}$

We included patients who were $>18$ years old, with a confirmed diagnosis of $\mathrm{CF},{ }^{10}$ and who had failed repeated trials of hypertonic saline via jet nebulizer. Per the American Association for Respiratory Care guidelines, we excluded patients with intracranial pressure $>20 \mathrm{~mm} \mathrm{Hg}$, hemodynamic instability, esophageal surgery, active hemoptysis, known or suspected tympanic membrane rupture or other middle-ear pathology, or untreated pneumothorax. ${ }^{11}$

\section{Treatments}

Each patient inhaled 2 puffs of albuterol (100 $\mu \mathrm{g} /$ puff) from a metered-dose inhaler, then $4 \mathrm{~mL}$ of $6 \%$ hypertonic saline (MucoClear, Pari Respiratory Equipment, Midlothian, Virginia) from the PEP system, which comprised a Porta-Neb compressor (dynamic pressure 11.7 psi, flow 6 L/min), a Pari PEP-System 1, and a Pari LC Plus nebulizer chamber. The respiratory therapist adjusted the resistance setting on the PEP device with a manometer attached to the PEP device's test dose port, to achieve an expiratory pressure resistance of $15-20 \mathrm{~cm} \mathrm{H}_{2} \mathrm{O}$. Spirometry was performed before and after the first dose. Patients who had stable spirometry $\left(<15 \% \mathrm{FEV}_{1}\right.$ decline $)$ continued with hypertonic saline treatment. Patients who had stable spirometry and tolerated the treatment were instructed to do the hypertonic saline treatments twice daily, after 2 puffs of albuterol (100 $\mu \mathrm{g} /$ puff), and then to proceed with their daily routine of autogenic drainage and nebulized antibiotics. The hypertonic saline was delivered via mouthpiece, without nasal clip, and with the resistance setting determined by the respiratory therapist, throughout the study period. Patients were also advised on nebulizer maintenance, as per the manufacturer's instructions.

\section{Exacerbations}

All patients were prospectively observed from recruitment to the pre-established common study end date of October 1, 2008. We recorded the number of days on intravenous antibiotics from enrollment to study end date, and compared the data from equal period before and after hypertonic saline commencement. We also calculated the mean time between the patients' 3 previous infective pulmonary exacerbations before hypertonic saline, and the time to next infective pulmonary exacerbation that required intravenous antibiotics, after initiating hypertonic saline.

\section{Adverse Effects}

Four weeks after PEP initiation, all 4 patients completed an adverse-effects questionnaire that was based on previous studies on hypertonic saline.,56 (Refer to the supplementary resources at http://www.rcjournal.com for the questionnaire.) On a 1-10 Likert-scale $(1=$ minimal, $10=$ intolerable) the patients graded cough, chest tightness, sore throat, and bad taste, for both jet nebulizer and PEP nebulizer.

\section{Statistical Analysis}

With statistics software (SPSS 15, SPSS, Chicago, Illinois), we used the Wilcoxon rank test to compare intravenous 
Table 1. Patients

\begin{tabular}{|c|c|c|c|c|c|c|c|}
\hline Patient & Sex & Genotype & $\begin{array}{c}\text { Body } \\
\text { Mass Index } \\
\left(\mathrm{kg} / \mathrm{m}^{2}\right)\end{array}$ & $\begin{array}{c}\text { Age } \\
\text { (y) }\end{array}$ & $\begin{array}{c}\text { Baseline } \\
\text { FEV }_{1} \\
\text { (\% predicted })\end{array}$ & $\begin{array}{c}\text { Baseline } \\
\text { FVC } \\
(\% \text { predicted })\end{array}$ & $\begin{array}{l}\text { Antibiotic Courses } \\
\text { in the Year Prior } \\
\text { to Hypertonic } \\
\text { Saline (no.) }\end{array}$ \\
\hline 1 & $\mathrm{~F}$ & $\Delta \mathrm{F} 508 / \Delta \mathrm{F} 508$ & 17 & 28 & 26 & 49 & 9 \\
\hline 2 & $\mathrm{~F}$ & 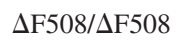 & 16 & 22 & 25 & 36 & 10 \\
\hline 3 & $\mathrm{~F}$ & $\Delta \mathrm{F} 508 / \Delta \mathrm{F} 508$ & 19 & 19 & 29 & 54 & 9 \\
\hline 4 & $\mathrm{~F}$ & $\Delta \mathrm{F} 508 / \Delta \mathrm{F} 508$ & 15 & 35 & 25 & 39 & 9 \\
\hline
\end{tabular}

Table 2. Antibiotic Days and Time to Next Exacerbation

\begin{tabular}{|c|c|c|c|c|c|c|c|}
\hline \multirow[b]{2}{*}{ Patient } & \multirow{2}{*}{$\begin{array}{c}\text { Patient's } \\
\text { Study Period } \\
\text { (d)* }\end{array}$} & \multicolumn{3}{|c|}{ Antibiotic Days, no. (\%) } & \multicolumn{3}{|c|}{ Days to Next Exacerbation } \\
\hline & & $\begin{array}{l}\text { Before } \\
\text { Hypertonic } \\
\text { Saline }\end{array}$ & $\begin{array}{l}\text { During } \\
\text { Hypertonic } \\
\text { Saline }\end{array}$ & Difference & $\begin{array}{c}\text { Before } \\
\text { Hypertonic } \\
\text { Saline (no.) }\end{array}$ & $\begin{array}{c}\text { During } \\
\text { Hypertonic } \\
\text { Saline (no.) }\end{array}$ & $\begin{array}{c}\text { Difference } \\
\text { no. }(\%)\end{array}$ \\
\hline 1 & 77 & $45(58)$ & $20(23)$ & $25(32)$ & 10 & 41 & $31(40)$ \\
\hline 2 & 92 & $66(72)$ & $14(15)$ & $52(57)$ & 8 & 65 & $57(62)$ \\
\hline 3 & 128 & $28(22)$ & $0(0)$ & $28(100)$ & 32 & 128 & $96(75)$ \\
\hline 4 & 137 & $63(46)$ & $63(46)$ & $0(0)$ & 22 & 23 & $1(<1)$ \\
\hline
\end{tabular}

antibiotic requirement before and after hypertonic saline therapy, and exacerbation-free interval before and after therapy. We used a paired-sample $t$ test to compare the adverse effects scores.

\section{Results}

\section{Tolerance}

Of the 37 CF patients we saw in our center during the screening period who were prescribed twice-daily nebulized $6 \%$ hypertonic saline, 4 patients $(12 \%)$ failed to tolerate this therapy, despite repeated testing. Two patients had failed previous hypertonic saline trials secondary to severe bronchospasm $\left(\mathrm{FEV}_{1}\right.$ decrease of $\left.>15 \%\right)$ and chest tightness; one patient had intolerable cough; and one patient could not tolerate the taste, despite taking the medication for several days. We recruited those 4 patients, and they all tolerated hypertonic saline via PEP nebulizer for the full study duration (Table 1). All 4 patients had severe CF-related pulmonary disease, with $\mathrm{FEV}_{1}<30 \%$ of predicted and frequent infective pulmonary exacerbations (mean 9 intravenous antibiotic courses over the previous one-year period). All 4 patients were fully adherent to hypertonic saline via PEP nebulizer, for $77,92,128$, and 137 days, to the study end date.

\section{Exacerbations}

In patients 1,2 , and 3 , in the hypertonic saline period, antibiotic requirement decreased (53\% risk reduction in

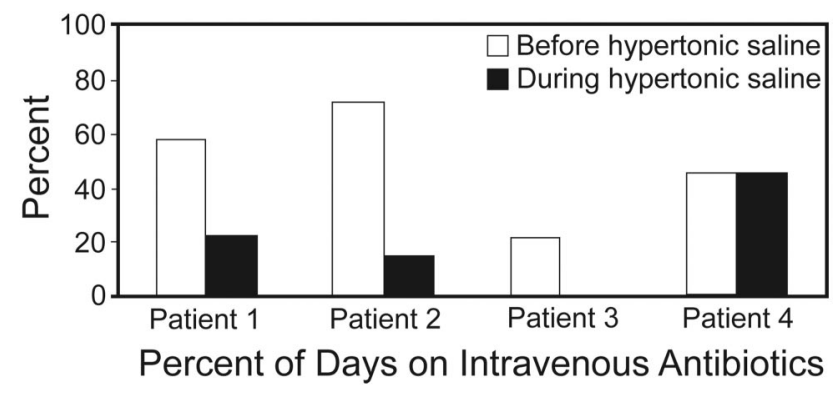

Fig. 1. Percent of days on intravenous antibiotics before and during hypertonic saline therapy.

antibiotic requirement, $P=.11$ ) (Table 2 and Fig. 1), and time to next infective pulmonary exacerbation requiring intravenous antibiotics increased (mean $18 \mathrm{~d}$ vs $64 \mathrm{~d}$, $P=.07$ ) (see Table 2 and Fig. 2).

\section{Adverse Effects}

The questionnaire responses indicated a $68 \%$ reduction in chest tightness; the mean Likert-scale score changed from 5.3 with jet nebulizer to 1.7 with PEP nebulizer $(P=.04)$. Mean cough score decreased $47 \%$, from 6.0 to $3.2(P=.10)$. Mean sore-throat score decreased $50 \%$, from 4.0 to $2.0(P=.20)$. Mean bad-taste score decreased $62 \%$, from 7.3 to $2.8(P=.06)$ (Fig. 3). No other adverse effects were reported with PEP nebulizer.

Advantages patients mentioned on the questionnaire included: "PEP therapy gives a clearer feeling at the end of 


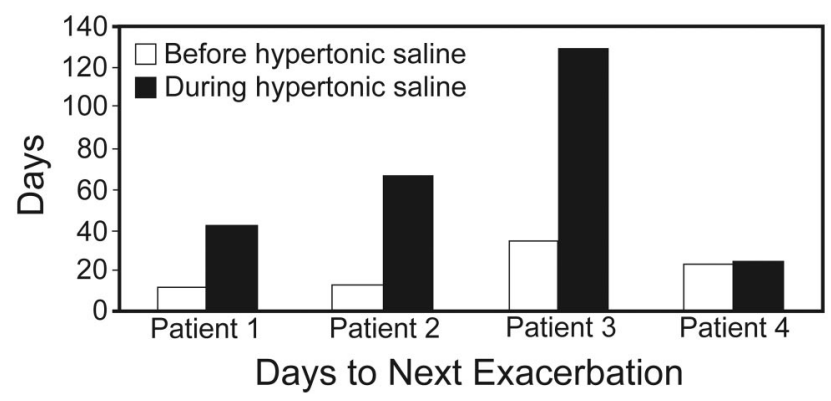

Fig. 2. Time to next infective pulmonary exacerbation before and during hypertonic saline therapy.

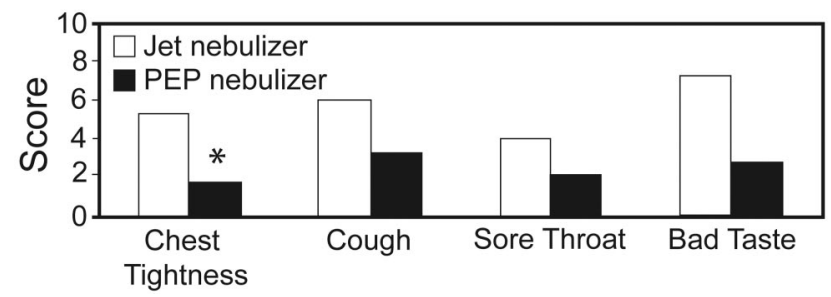

Fig. 3. Adverse effects of hypertonic saline administered via jet nebulizer versus positive-expiratory-pressure nebulizer. ( $\left.{ }^{\star} P=.04\right)$.

physiotherapy," "It makes doing chest physiotherapy much easier and less tiring," "You can vary the rate of flow," "It is easier to tolerate," "The resistance makes it easier to breath," and "The hypertonic saline does not taste as salty." The only subjective disadvantage noted was longer nebulization time.

\section{Discussion}

To our knowledge, this is the first report on administering hypertonic saline via PEP nebulizer in CF patients who were intolerant of hypertonic saline via jet nebulizer despite multiple trials. The benefits of hypertonic saline are well established, but almost $10 \%$ of CF patients are intolerant of hypertonic saline via jet nebulizer, predominantly secondary to cough, bad taste, and bronchospasm. ${ }^{5}$ This case series demonstrates 4 such patients who were recurrently intolerant of hypertonic saline, all of whom tolerated hypertonic saline via PEP nebulizer. In addition to tolerability and full adherence to therapy, there was a trend toward fewer infective pulmonary exacerbations and increased time to next pulmonary exacerbation. Our finding of a 53\% reduction in antibiotic use during the PEP period is comparable to that of a previous study that found a $56 \%$ reduction in CF pulmonary exacerbation rate after hypertonic saline initiation. ${ }^{5}$

It is also important to highlight that all patients in this case series had very severe CF pulmonary disease (mean $\mathrm{FEV}_{1} 26 \%$ of predicted). CF patients with severe pulmonary disease often are already receiving maximal therapy, with limited additional prophylactic strategies available. Given the established benefits of hypertonic saline, ${ }^{5}$ administration via PEP nebulizer is a useful adjunct for pa- tients intolerant of jet nebulization, and may aid in bridging these patients to lung transplantation.

There was a $68 \%$ reduction in chest tightness with hypertonic saline via PEP nebulizer. Hypertonic saline causes transient airway narrowing in $30 \%$ of CF patients. ${ }^{11}$ PEP nebulizer probably causes bronchodilation by splinting open the airways, reducing bronchospasm, and reducing bronchoconstriction-induced cough. ${ }^{8}$ PEP also increases expiratory time, tidal volume, and minute ventilation, and decreases respiratory rate, allowing for a more optimal breathing pattern and improved pulmonary aerosol deposition. ${ }^{12,13}$ PEP can also augment collateral ventilation and improve mucociliary clearance toward central bronchioles. ${ }^{14,15}$ These benefits are supported by 2 studies that found up to $30 \%$ increased peripheral airway deposition of radio-labeled aerosol particles with pressure support and PEP nebulizer in CF patients. ${ }^{13,16}$ Given the propensity of hypertonic aerosol droplets to undergo hygroscopic growth in the respiratory tract, resulting in a more central particle deposition, ${ }^{17}$ the increased peripheral deposition of hypertonic saline with PEP nebulizer ${ }^{18}$ helps target the areas most affected by infection and inflammation in the $\mathrm{CF}$ lung, potentially leading to a synergistic effect between the PEP nebulizer and hypertonic saline. That said, the benefits of smaller particle size and the moderate increase in peripheral lung deposition with PEP may be offset by a significant reduction in lung particle deposition with PEP. ${ }^{18}$ This reduction in lung particle deposition could be reduced by the use of an "interrupter," which should decrease aerosol loss through the flow-resistance orifice of the PEP system during exhalation. ${ }^{18}$ Further work on this is needed.

We found a clinically important (but nonsignificant) $47 \%$ reduction in cough with PEP. The mechanism of hypertonic-saline-induced cough is thought to be impaction and irritation of large aerosol particles in the upper airway during inhalation, resulting in a nonspecific mechanical irritation of the laryngeal rapidly adapting receptors. ${ }^{19}$ A higher aerosolization flow rate increases aerosol deposition in the oropharynx, ${ }^{16}$ which is probably a component of intolerable cough and bronchospasm in many patients with jet-nebulized hypertonic saline. ${ }^{12}$ Two of our patients mentioned the ability to vary the flow rate with PEP to be advantageous. Additionally, PEP nebulizer reduces oropharyngeal aerosol deposition, reducing irritation of the rapidly adapting receptors and cough. ${ }^{16}$

Another advantage reported by our patients was easier sputum expectoration after hypertonic saline. There are a number of mechanisms described for the therapeutic benefits of hypertonic saline in CF patients. In addition to osmotically restoring the airway surface liquid, ${ }^{20}$ hypertonic saline also increases the ionic concentration of the mucus, shielding the negative charges and resulting in a more compact mucus macromolecule, allowing for more effective airway clearance. ${ }^{21}$ Hypertonic saline also affects the ionic bonds in mu- 
cus, reducing viscosity and elasticity. ${ }^{22}$ More recent studies found significant anti-inflammatory and antimicrobial properties of hypertonic saline, including the activation of the anti-microbial peptide LL-37 through the disruption of anionic matrices, ${ }^{23}$ and an effect on Pseudomonas aeruginosa motility and quorum sensing. ${ }^{24}$ The suggestion that the benefits of hypertonic saline in CF patients are attributable to increased cough induction were refuted in clinical studies involving matched voluntary coughs. ${ }^{21}$

\section{Limitations}

Our sample size was relatively small and we did not establish whether the benefits we observed were a result of the hypertonic saline or the PEP nebulizer alone, or due to a synergistic effect. That said, the $100 \%$ tolerance of hypertonic saline via PEP nebulizer in these 4 patients with very severe $\mathrm{CF}$ lung disease cannot be ignored. Additionally, we used $6 \%$ hypertonic saline, as this was the only commercially available, preservative-free hypertonic saline available in Ireland at the time of the study, but the patients' previous intolerance of hypertonic saline was established on the same $6 \%$ solution.

\section{Conclusions}

This report highlights a novel method of administering hypertonic saline to CF patients who have previously failed hypertonic saline via jet nebulizer, which merits a larger, multicenter prospective study.

\section{REFERENCES}

1. Cashman SM, Patino A, Delgado MG, Byrne L, Denham B, De Arce M. The Irish cystic fibrosis database. J Med Genet 1995;32(12):972975.

2. Ratjen F, Döring G. Cystic fibrosis. Lancet 2003;361(9358):681-689.

3. Sheppard DN, Welsh MJ. Structure and function of the CFTR chloride channel. Physiol Rev 1999;79(Suppl 1):S23-S45.

4. Matsui H, Grubb BR, Tarran R, Randell SH, Gatzy JT, Davis CW, Boucher RC. Evidence for periciliary liquid layer depletion, not abnormal ion composition, in the pathogenesis of cystic fibrosis. Cell 1998;95(7):1005-1015.

5. Elkins MR, Robinson M, Rose BR, Harbour C, Moriarty CP, Bye $\mathrm{PT}$, et al. A controlled trial of long term inhaled hypertonic saline in patients with cystic fibrosis. N Engl J Med 2006;354(3):229-240.

6. Donaldson SH, Bennett WD, Zeman KL, Knowles MR, Tarran R, Boucher RC. Mucus clearance and lung function in cystic fibrosis with hypertonic saline. N Engl J Med 2006;354(3):241-250.
7. Mahlmeister M, Fink JB, Hoffman G, Fifer LF. Positive-expiratorypressure mask therapy: theoretical and practical considerations and a review of the literature. Respir Care 1991;36(11):1218-1229.

8. Klausen NO, Andersen JB. A new mode of administration of nebulized bronchodilators in severe bronchospasm. Eur J Respir Dis Suppl 1982;197:97-100.

9. Rodwell LT, Anderson SD. Airway responsiveness to hyperosmolar saline challenge in cystic fibrosis: a pilot study. Pediatr Pulmonol 1996;21(5):282-289.

10. Welsh M, Ramsey BW, Accurso F, Cutting CR. Cystic fibrosis. In: Scriver CR, Beaudet AL, Sly WS, Valle D, editors. The molecular and metabolic basis of inherited disease, 8th edition. New York: McGraw-Hill; 2001:5121-5188.

11. American Association for Respiratory Care clinical practice guideline: use of positive airway pressure adjuncts to bronchial hygiene therapy. Respir Care 1993;38(5):516-521.

12. Fahy JV, Wong HH, Geppetti P, Reis JM, Harris SC, Maclean DB, et al. Effect of an NK1 receptor antagonist (CP-99,994) on hypertonic saline induced bronchoconstriction and cough in male asthmatic subjects. Am J Respir Crit Care Med 1995;152(3):879-884.

13. Newman SP, Pavia D, Garland N, Clarke SW. Effects of various inhalation modes on the deposition of radioactive pressurised aerosols. Eur J Respir Dis 1982;63(119):57-65.

14. Andersen JB, Qvist J, Kann T. Recruiting collapsed lung through collateral channels with positive end-expiratory pressure. Scand J Respir Dis 1979;(60):260-266.

15. Meduri GU, Cook TR, Turner RE, Cohen M, Leeper KV. Noninvasive positive pressure ventilation in status asthmaticus. Chest 1996; 110(3):767-774.

16. Fauroux B, Itti E, Pigeot J, Isabey D, Meignan M, Ferry G, et al. Optimization of aerosol deposition by pressure support in children with cystic fibrosis: an experimental and clinical study. Am J Respir Crit Care Med 2000;162(6):2265-2271.

17. Chan HK, Eberl S, Daviskas E, Constable C, Young I. Changes in lung deposition of aerosols due to hygroscopic growth: a fast SPECT study. J Aerosol Med 2002;15(3):307-311.

18. Laube BL, Gellar DE, Lin TC, Dalby RN, Diner-West M, Zeitlin PL. Positive expiratory pressure changes aerosol distribution in patients with cystic fibrosis. Respir Care 2005;50(11):1438-1444.

19. Sant'Ambrogio G, Widdicombe J. Reflexes from airway rapidly adapting receptors. Respir Physiol 2001;125(1-2):33-45.

20. Rogers D. Mucoactive agents for airway mucus hypersecretory diseases. Respir Care 2007;52(9):1176-1193.

21. Robinson M, Hemming AL, Regnis JA, Wong AG, Bailey DL, Bye PT, et al. Effect of increasing doses of hypertonic saline on mucociliary clearance in patients with cystic fibrosis. Thorax 1997;52(10):900-903.

22. Ziment I. Respiratory pharmacology and therapeutics. Philadelphia: WB Saunders; 1978:60-104.

23. Bergsson G, Reeves E, McNally P, Chotirmall SH, Greene CM, Greally P, et al. LL-37 complexation with glycosaminoglycans in cystic fibrosis inhibits antimicrobial activity, which can be restored by hypertonic saline. J Immunol 2009;183(1):543-551.

24. Havasi V, Hurst CO, Briles TC, Yang F, Bains DG, Hassett DJ, Sorscher E. Inhibitory effects of hypertonic saline on P. aeruginosa motility. J Cyst Fibros 2008;7(4):267-269.

This article is approved for Continuing Respiratory Care Education credit. For information and to obtain your CRCE

(free to AARC members) visit www.RCJournal.com

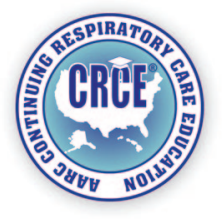

